\title{
Analyzing the Characteristics and Causes of Location Spatial Agglomeration of Listed Companies: An Empirical Study of China's Yangtze River Economic Belt
}

\author{
Deyu Meng, ${ }^{1}$ Guoen Wei $\left(\mathbb{D},{ }^{2}\right.$ and Pingjun Sun ${ }^{3}{ }^{3}$ \\ ${ }^{1}$ College of Management, Qingdao Agricultural University, Qingdao 266109, China \\ ${ }^{2}$ College of Geography and Ocean Sciences, Nanjing University, Nanjing 210023, China \\ ${ }^{3}$ College of Geographical Sciences, Southwest University, Chongqing 400700, China
}

Correspondence should be addressed to Pingjun Sun; sunpj031@nenu.edu.cn

Received 12 September 2020; Revised 14 November 2020; Accepted 28 November 2020; Published 10 December 2020

Academic Editor: Huajiao Li

Copyright (C) 2020 Deyu Meng et al. This is an open access article distributed under the Creative Commons Attribution License, which permits unrestricted use, distribution, and reproduction in any medium, provided the original work is properly cited.

Enhancing urban development vitality and optimizing the allocation of regional industrial factors require a comprehensive analysis of listed companies, such as the overall distribution network, agglomeration evolution trend, industrialization layout, and driving mechanism. Using 1,624 A-share listed companies in China's Yangtze River Economic Belt as research area, this study integrated trend surface analysis (TSA), exploratory spatial data analysis (ESDA), standard deviation ellipse (SDE), and spatial regression model methods. The main results are as follows: (1) The overall quantity scale of the listed companies in the Yangtze River Economic Belt has achieved significant growth, but the spatial difference of location selection persists. The spatial configuration formed a hierarchical urban distribution pattern with the Yangtze River Delta region as the agglomeration core and the provincial capitals as the fulcrum. (2) Listed companies accelerate the expansion of the Yangtze River Delta region. Chengdu, Wuhan, Changsha, and other central-western provincial capitals gradually increased the region's attractiveness. High-high and low-low agglomerations remain the main forms of agglomeration. (3) There are significant differences in the location selection of listed companies with varying specialization levels, forming a relatively different alienated high-value distribution structure among various industry types. (4) The levels of knowledge spillover, city scale, and policy support level are major factors affecting the location selection process of listed companies in the Yangtze River Economic Belt. For low-level city network with few listed companies, city scale and knowledge spillover levels are significant determinants for the development of headquarters' economy. For high-level city network, along with the level of knowledge spillovers and policy support, globalization level has an important contribution to the shaping of the location advantages of attracting the layout of listed companies.

\section{Introduction}

With the rise of cross-border trade and emerging technological revolutions, the dominant production factor inputs have been gradually shifting from capital and labor into innovation, technology, and information. Listed companies have increasingly provided crucial support to regional organizations to participate in the global market competition under the new normal of economic development. These enterprises have become a new type of "carriage," promoting sustainable development in the modern national economy and playing a leading role in guiding technology development. They have also been essential in integrating scientific and technological inventions, promoting industrial upgrading, and meeting social development needs in the regional product development chain [1]. A listed company is a market-oriented modern enterprise formed by the agglomeration of various production factors. It reflects the level of capital securitization and direct financing capacity of a particular region and, to a certain extent, represents the dominant position of a country or region in the global division of labor system and the international innovation pattern $[2,3]$.

Affected by regional policy adjustments and changes in corporate business strategies, the location selection and 
distribution law of listed companies in emerging developing countries represented by China has been changed consistently in recent years. This has resulted in changes to the industrial innovation strength and production agglomeration pattern and has created an incentive effect on the allocation optimization of regional production factors and reward mechanisms for industries. Researching location spatial agglomeration of listed companies is particularly important for emerging economies in the growth period of capital markets [4]. The evolution and development of density, scale, and operating performance are mainstream research areas in analyzing the spatial agglomeration of listed companies, using various methods, such as nuclear density [5], spatial autocorrelation [6], Gini coefficient [7], and location quotient [8]. Majority of the studies have focused on country, state, and provincial levels $[2,9]$ and have paid little attention to the change of attractiveness of new urban forms (e.g., urban agglomerations, metropolitan areas, and economic belts) in the location selection of listed companies. Moreover, adapting to the rapid development of urbanization and urban hierarchical systems in emerging countries is complex and difficult. Thus, establishing a comprehensive analytical framework with multiple methods is essential for the study of the location of spatial agglomeration of listed companies in the new urban agglomeration.

Along with the opportunities and challenges brought about by the transformation of the industrial structure in emerging economies, the basic roles of listed companies in urban development and upgrading of industrial parks have been continuously improved; recent studies have focused on enhancing regional location attractiveness to listed companies and analyzing the driving mechanism of the location selection of listed companies [10,11]. Urban geographical location, financial prosperity, knowledge spillover effect, and export-oriented economic scale are considered as critical elements for the spatial layout of headquarters. The internal and external structural elements of sociology and management (e.g., entrepreneur's investment motives, policy support, innovation reward of enterprises, and demonstration driving effect of scale agglomeration) are also being considered as important components $[6,12]$. In terms of driving mechanism research, the influence of geospatial elements on the location of spatial agglomeration of listed companies can be difficult to analyze using traditional approaches, such as least squares regression and panel Tobit regression. Therefore, exploring the driving influence of spatial dependence on the location selection of listed companies is necessary for optimizing the layout structure of listed companies and formulating investment promotion strategies of industrial parks and regions that enhance location's attractiveness.

The study area is the Yangtze River Economic Belt (YEB), one of the highest economic density areas in China, which covers 11 provincial administrative regions, namely, Shanghai, Jiangsu, Zhejiang, Anhui, Jiangxi, Hubei, Hunan, Sichuan, Chongqing, Yunnan, and Guizhou (Figure 1). The region has a high total economic value and sizeable industrial sector $[13,14]$. Its vibrant atmosphere for innovation and creativity has formed a spatial economic cluster of listed companies based on national central cities (e.g., Shanghai, Wuhan, Chongqing, Chengdu) and urban agglomerations (e.g., the Yangtze River Delta, urban agglomerations in the middle reaches of the Yangtze River, and Chengdu-Chongqing urban agglomeration) [15]. The regional differences in the location selection of listed companies and the "path-dependent effect" of regional headquarters economy development are becoming more and more obvious, bringing challenges to the allocation of urban factor resources and the sustainable development of industries in the YEB region [7]. Therefore, to measure the spatial agglomeration evolution of the listed companies and to explore the driving mechanism of location selection become an important basis promoting the rational layout of industrial factors and realizing the overall sustainable economic development of the YEB region.

Based on the concepts of regional coordinated development and enterprise management to build the analysis framework of "pattern evolution-typical alienation-driving mechanism," trend surface analysis (TSA), exploratory spatial data analysis (ESDA), standard deviation ellipse (SDE), and location quotient model (LQM) were employed to analyze the location characteristics of spatial agglomerations of the listed companies. GIS technology and spatial regression model are used to analyze the driving mechanism that affects the spatial agglomeration of listed companies from the perspective of the overall and "typical regions" (stratification of the regional city network system based on the quantity of listed companies). This study intends to focus on solving two research problems: (1) to reveal the evolution characteristics of spatial agglomeration of the location selection of listed companies in the YEB region; (2) to clearly explore the key factors of the city network with different scales of listed companies in the YEB region to attract and cultivate listed companies. By solving these problems, this study aims to provide a basis for fully understanding the spatial preference and temporal changes of the location selection of listed companies in the YEB region and provide targeted suggestions for improving the networked layout of listed companies in the YEB region, as well as different levels of city networks along the line to enhance the location attractiveness of listed companies and shape the location advantages of industrial agglomeration.

\section{Materials and Methods}

2.1. Research Methods. This study adopts the "pattern evolution-typical alienation-driving mechanism" framework (Figure 2) and is composed of two main components: (1) pattern evolution and (2) typical alienation and driving mechanism. In pattern evolution analysis, the spatial agglomeration characteristics of listed companies are explored in terms of overall distribution network, agglomeration evolution trend, industrialization layout using GIS spatial interpolation, trend surface analysis, exploratory spatial data analysis method, standard deviation ellipse, and location quotient. For typical alienation and driving mechanism analysis, based on the clustering of the distribution of listed 

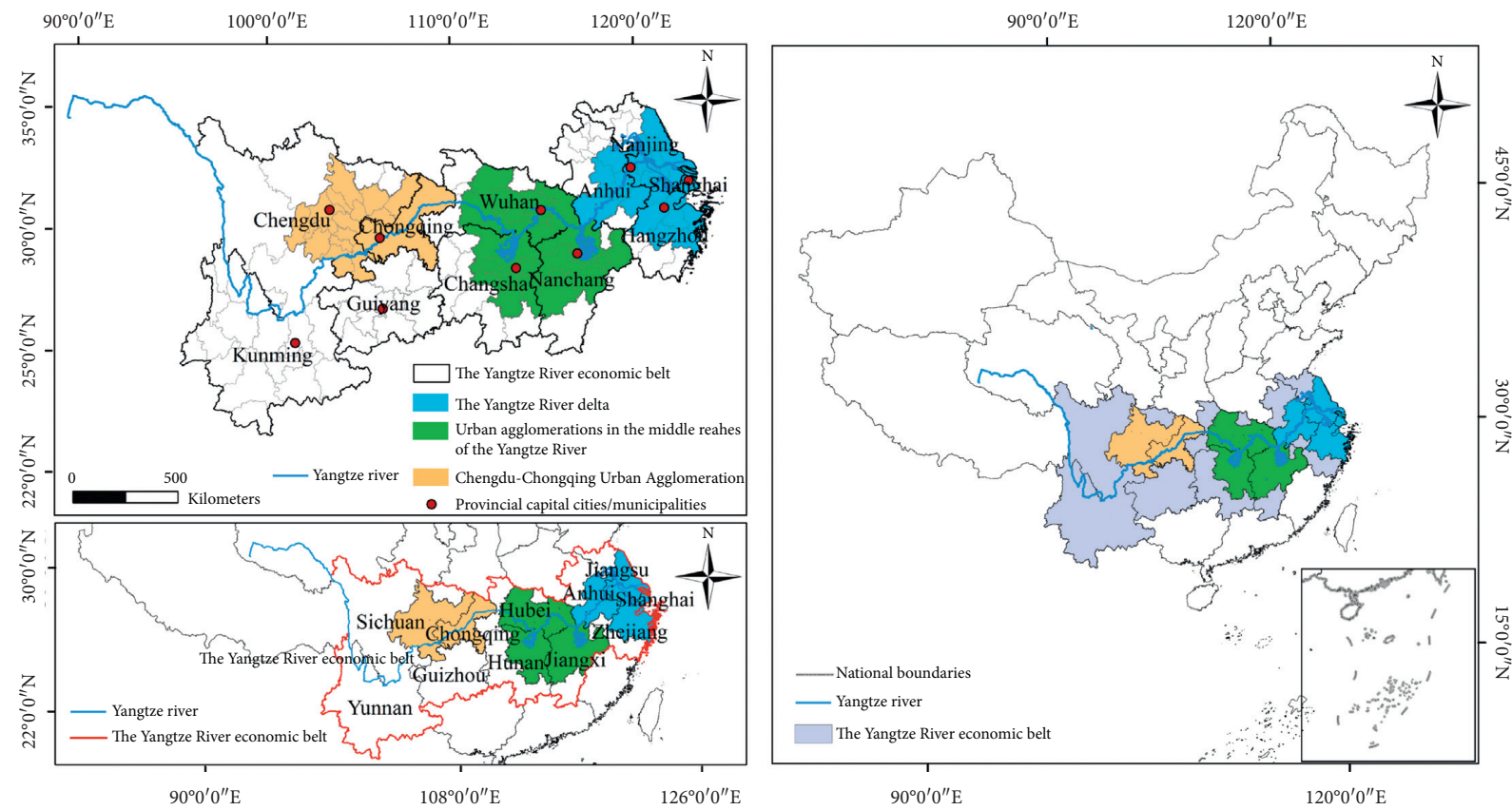

FIGURE 1: Geographical location map of the YEB region.

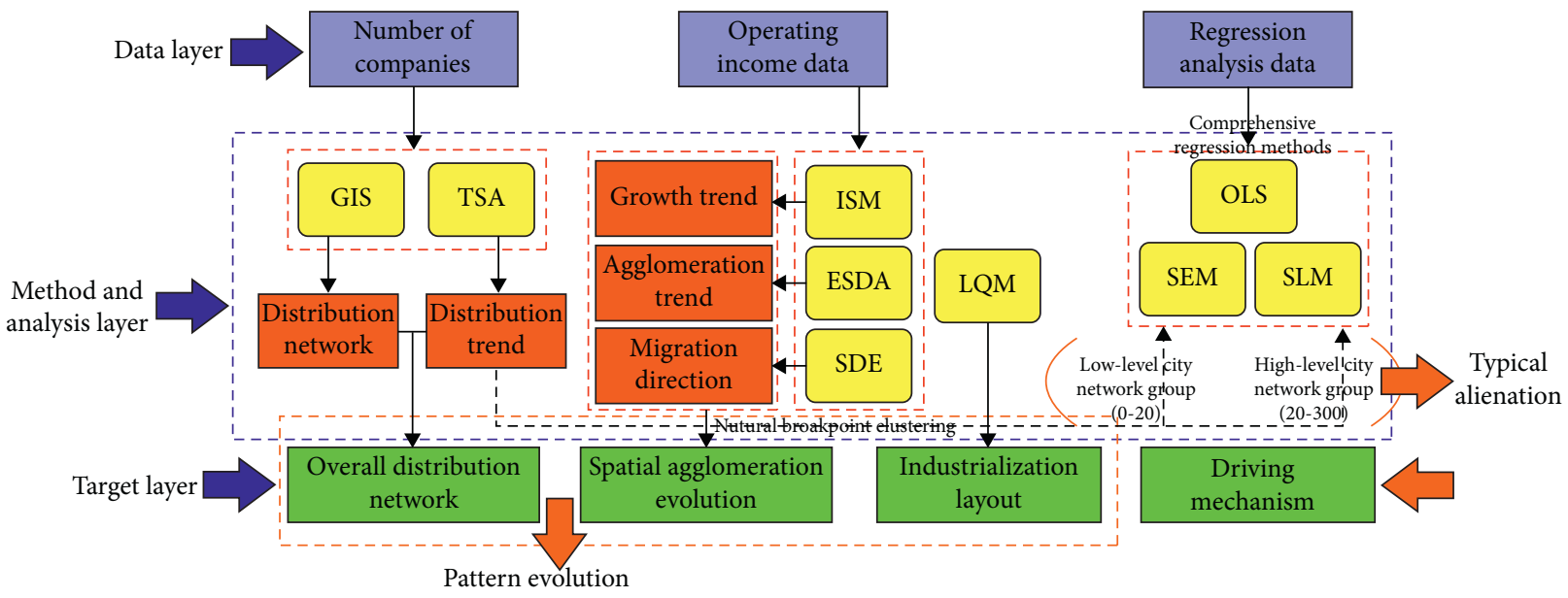

Figure 2: Research ideas framework.

companies, the "typical regions" are divided into two types, low-level city network with few listed companies and highlevel city network with a large number of listed companies, which is taken as the basis for the cities which have different scales of listed companies to adopt targeted strategies to develop headquarters economy. The OLS model, spatial lag model, and the spatial error model are employed to analyze the driving mechanism of the spatial agglomeration of listed companies for the entire area and for "typical regions." The research ideas and the functions of each method are shown in Figure 2.
2.1.1. Trend Surface Analysis. The trend surface is an approximate processing result. This method fits the observation points to a trend line in the form of trend gradient on the orthogonal plane formed by the $X$ axis and the $Y$ axis, which can simulate the difference in spatial distribution trends of listed companies in the north-south and east-west directions. The formula is as follows:

$$
z_{i}\left(x_{i}, y_{i}\right)=T_{i}\left(x_{i}, y_{i}\right)+\varepsilon_{i},
$$

where $\left(x_{i}, y_{i}\right)$ are the planar spatial coordinates; $x$ and $y$ represent the east-west and north-south directions in 
geographic space, respectively. $z_{i}\left(x_{i}, y_{i}\right)$ is the number of listed companies. $T_{i}\left(x_{i}, y_{i}\right)$ represents the trend value of the number of listed companies in the range. The Trend Surface tool in ArcGIS software was used to describe the trend of the observed values [16].

\subsubsection{Exploratory Spatial Data Analysis}

(1) Global Spatial Autocorrelation. The global spatial autocorrelation method is used to analyze the spatial agglomeration of listed companies. Global Moran's I index can reflect the spatial autocorrelation of geographical elements distribution, which is given by the following expression:

$$
\text { Moran's } I=\frac{\sum_{i=1}^{n} \sum_{i=1}^{n} W_{i j}\left(x_{i}-\bar{x}\right)\left(x_{j}-\bar{x}\right)}{\sum_{i=1}^{n}\left|x_{j}-\bar{x}\right|^{2} \sum_{i=1}^{n} \sum_{j=1}^{n} W_{i j}},
$$

where $i$ and $j$ are the numbers of listed companies in the region and $W_{i j}$ is a spatial weight matrix. Moran's I values fall within the range $[-1,1]$. When the value is positive, the observation is positively correlated in spatial distribution, and when the value is negative, the correlation is negative. When the value is 0 , the distribution of the observed value is random.

(2) Local Spatial Autocorrelation. The local spatial autocorrelation can be used to comprehensively reflect the regional variability of the spatial agglomeration. In this study, we used local Moran's I to test the regional variability of the spatial agglomeration of listed companies, which are given by the expressions

$$
\begin{aligned}
\text { local Moran's } I & =\frac{\left(x_{i}-\bar{x}\right)}{S^{2}} \sum_{j=1}^{n} W_{i j}\left(x_{j}-\bar{x}\right), \\
S^{2} & =\frac{1}{n} \sum_{i=1}^{n}\left(x_{i}-\bar{x}\right)^{2} .
\end{aligned}
$$

A positive index value indicates that the region-adjacent units are close to an agglomeration with similar value. When the index is negative, the adjacent units are heterogeneous.

2.1.3. Standard Deviation Ellipse. This method mainly includes three elements: angle $\theta$, long axis standard deviation, and short-axis standard deviation, which are used to reflect the degree of geographic concentration, the dominant distribution direction, and the migration direction of center-ofgravity of listed companies in the YEB region. The formula for the center-of-gravity coordinates is

$$
\begin{aligned}
& \bar{X}_{w}=\frac{\sum_{i=1}^{n} w_{i} x_{i}}{\sum_{i=1}^{n} w_{i}}, \\
& \bar{Y}_{w}=\frac{\sum_{i=1}^{n} w_{i} y_{i}}{\sum_{i=1}^{n} w_{i}},
\end{aligned}
$$

such that $\left(x_{i}, y_{i}\right)$ is the spatial location of provincial units and $w_{i}$ is the spatial weight of provincial units.
2.1.4. Location Quotient of Specialization Level. The location quotient method is used to measure the location selection preference of listed companies with different specialization levels under the industry classification of the YEB region [8]. We used the total operating income data of listed companies as the measurement indicators and divided the whole industry into labor-intensive industries, capital-intensive industries and technology-intensive industries based on the Dongcai industry classification. The specific classification rules are as follows: Listed companies in household appliances, food and beverage, apparel and textiles, trade and retail, and light industry manufacturing were classified as labor-intensive industries. Listed companies in real estate, steel, utilities, basic chemicals, building materials, nonferrous metals, and transportation were classified as capitalintensive industries. Listed companies in defense military industry, mechanical equipment, computers, automobiles, medical biology, and computer networks were classified as technology-intensive industries.

2.1.5. Regression Analysis Model. A comprehensive regression model was employed to analyze the factors affecting the spatial agglomeration characteristics of listed companies in the YEB region and "typical regions." The methodology includes the use of the OLS model, the spatial error model (SEM), and the spatial lag model (SLM) and selects the optimal model based on the goodness of fit, Schwarz criterion, and Akaike information criterion. The OLS model is a traditional regression model based on the least square method. The SEM focuses on unobservable spatial dependence between variables and can detect the spatial interaction effect between error terms. The SLM emphasizes the neighborhood effect and focuses on the overlooked spatial interdependence between dependent variables and can detect the influence of spatial distance on behavior [17]. The formula of the OLS model is not introduced. For the SLM, the formula is as follows:

$$
\begin{aligned}
& y=\sigma w_{i j} y_{i}+x_{i} \beta+\varepsilon_{i}, \\
& \varepsilon_{i} \sim N\left(0, \sigma^{2} I\right),
\end{aligned}
$$

where $y$ is the number of listed companies in the city; $x$ is the influencing factor affecting the layout of listed companies; $\beta$ is the coefficients of the regression model, which is related to the explanatory power of the influencing factors on the spatial agglomeration of listed companies; and $\varepsilon$ is a random error.

The SEM is given by the expression

$$
y=x_{i} \beta+\lambda w_{i j} \varepsilon_{j}+\mu_{i}
$$

where $\lambda$ is the parameter for the spatial correlation strength between residuals and $\mu_{i}$ is a random disturbance term.

2.2. Data Sources. In this study, all the A-share listed companies (704 companies in 2008, 1624 companies in 2017 ) in 126 cities in total along the YEB region were used in the analysis, with the research period from 2008 to 2017. The 
research starting point (2008) coincides with the beginning of the global financial crisis, analyzing the spatial agglomeration characteristics and causes of listed companies in the YEB region in the post-financial crisis era. Prefecture-level cities were used as the basic geographical unit in the study. Attribute information, securities code, industry category, and city of listed companies were derived mainly from the Choice, Wind, and CSMAR databases in China and were appended with the corresponding company's spatial information. Additional data on the factors affecting spatial distribution were derived from City Statistical Yearbook and City Statistical Bulletin.

\section{Results}

\subsection{The Spatiotemporal Evolution of the Location of Spatial Agglomeration of Listed Companies}

3.1.1. Overall Distribution Network Analysis. Figures 3 and 4 present the spatial agglomeration of listed companies along the YEB region in various provinces and regions. The listed companies are mainly concentrated in the Yangtze River Delta region, forming a hierarchical regional layout network that has the Yangtze River Delta region as the agglomeration core, the Yangtze River as the primary link, and the provincial capitals as fulcrums. For the given study period, the number of listed companies in the YEB region increased rapidly, from 704 in 2008 and 1097 in 2013 to 1624 in 2017. In the Yangtze River Delta area, listed companies accounted for $63.2 \%$ (2008), $67.9 \%$ (2013), and 71.6\% (2017) of the total study area. Shanghai, Jiangsu, and Zhejiang have led the sustained development of the headquarters economy in the YEB region. In contrast, Guizhou, Chongqing, Yunnan, Jiangxi, and other central and western provinces with relatively slow economic development have fewer listed companies. This suggests that the location selection of listed companies in the YEB region has significant regional differences and the economic development of headquarters in each province is not balanced. The headquarters economy in the Yangtze River Delta region has been actively expanding, probably due to factors such as the economic strength advantage and economic externalities. The scale of listed companies around the provincial capital cities has grown significantly. In 2008, Shanghai and Hangzhou were at the forefront in terms of the number of listed companies. By 2017, the listed companies in Chongqing, Chengdu, Changsha, Wuhan, Nanjing, and other provincial capital cities have increased in magnitude from the third echelon to the second echelon. This suggests that as the provincial capital cities continue to siphon resource elements (e.g., technology, labor services, and capital), the location's attractiveness is increasing for listed companies.

Figure 5 shows the trends in the distribution of listed companies. The listed companies in the YEB region exhibit the following spatial distribution trend: "the quantity of companies is high in the northeast and low in the southwest." The east-west direction presents a U-shaped structure which is raised at both ends and dipping in the middle. The results also show that over time the upward momentum of the eastern region has decelerated. The overall quantity scale of listed companies in the central and western regions is weaker than in the eastern regions, but this gap is significantly shrinking. In the north-south direction, the slope line rises from south to north, and the value of the slope has gradually decreased over time. This indicates that the overall quantity scale of listed companies in the northern region is larger than in the southern region and that this difference has shrunk over time. This contraction in scale disparity between the northern and southern regions may be related to the rapid development of headquarters economy in Zhejiang and Hunan provinces.

\subsubsection{Spatial Agglomeration Evolution Analysis}

(1) Growth Trend Evolution Analysis of Listed Companies. Figure 6 shows the evolution trend of quantity growth transfer of listed companies based on the comprehensive division of incremental subtraction and natural breakpoint classification method. The cities in the YEB region are divided into four categories: unchanged regions (0), slow growth (1-15), rapid growth (15-45), and extreme growth (45-90). In terms of growth structure, we found that the quantity growth structure of listed companies in the YEB region has been relatively stable, with the majority classified as unchanged or having slow growth. The proportion of the area of unchanged regions was $51.9 \%$ for the periods of 2008-2013 and 2013-2017, while the proportions of those with slow growth were $44.3 \%$ and $38.9 \%$, respectively. In terms of spatial characteristics, the scale transfer classification shows significant regional heterogeneity. Rapid growth and extreme growth are concentrated in the Yangtze River Delta region, with Shanghai and Hangzhou being core to form the core peripheral structure of the incremental gradient attenuation. This reflects the city grade gradient difference and the core edge diffusion effect of the location's attractiveness. Slow growth cities in the central and western regions are spatially fragmented. Over time, the quantity scale of listed companies has increased in a number of cities, including Chengdu, Wuhan, and Changsha, and the trend evolution pattern of listed companies in the central and western regions has gradually formed around the agglomeration of provincial capital cities.

(2). Analysis of the Trend of Spatial Agglomeration and Concentration Scope of Listed Companies. Table 1 summarizes the change in the global autocorrelation index, and Figure 7 presents the evolution of local autocorrelation trend and spatial center-of-gravity. In terms of the evolution of spatial agglomeration distribution, the results show a significant spatial agglomeration trend, with high-high and low-low agglomerations distributed in the east and west regions, respectively. In the global autocorrelation analysis, global Moran's I index values for 2008, 2013, and 2017 are $0.128,0.228$, and 0.283 , respectively. The $z$-test values have become more significant, reflecting the continued increase in the spatial concentration of listed companies in the YEB region. In the local autocorrelation analysis, we employed 


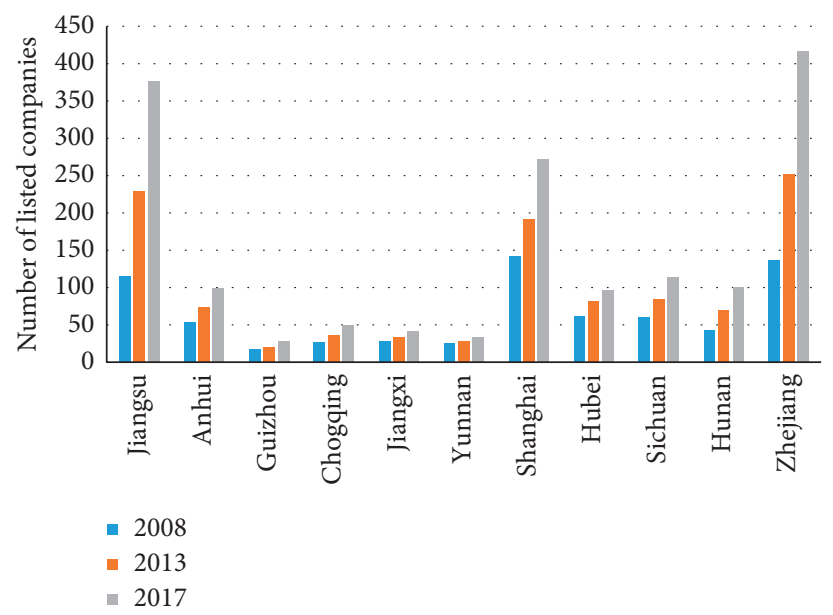

FIgURE 3: The distribution of listed companies in the provinces of the YEB region in 2008, 2013, and 2017.
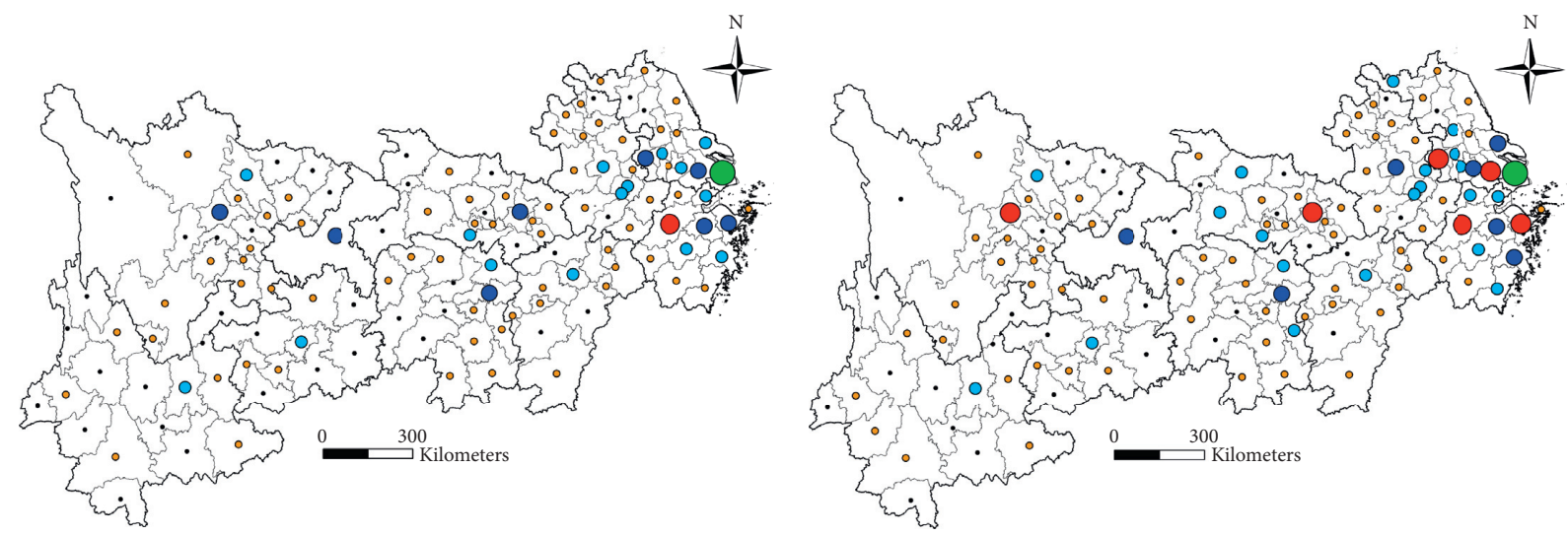

Number of listed

companies

- Null

- $21-40$

- $0-5$

- $41-100$

Number of listed

companies

o $5-20$

101-300

- Null

21-40

- 0-5

- 41-100

(a)

(b)

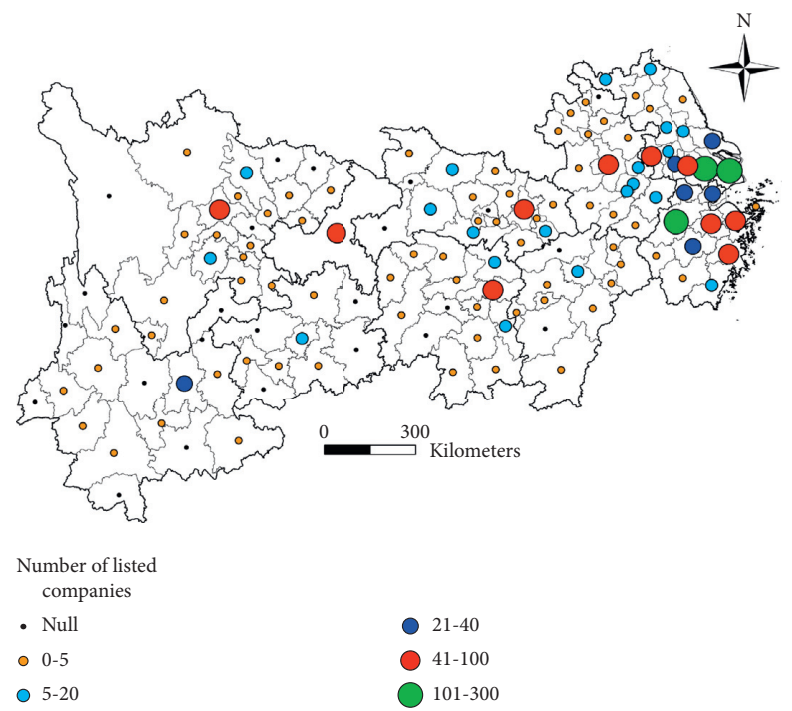

(c)

FIgURE 4: The distribution network of listed companies in cities of the YEB region in (a) 2008, (b) 2013, and (c) 2017. 


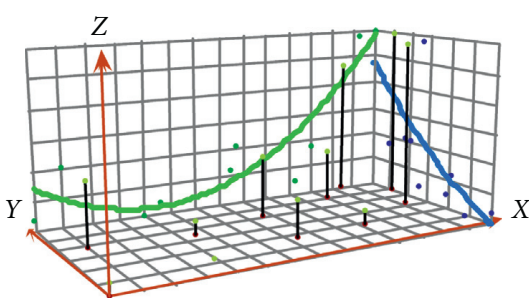

(a)

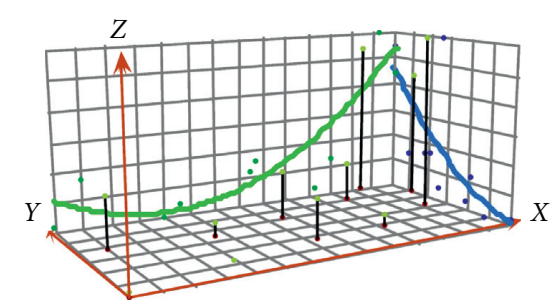

(b)

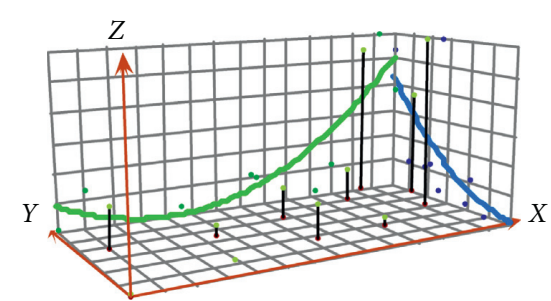

(c)

Figure 5: The trend distribution of listed companies in (a) 2008, (b) 2013, and (c) 2017.

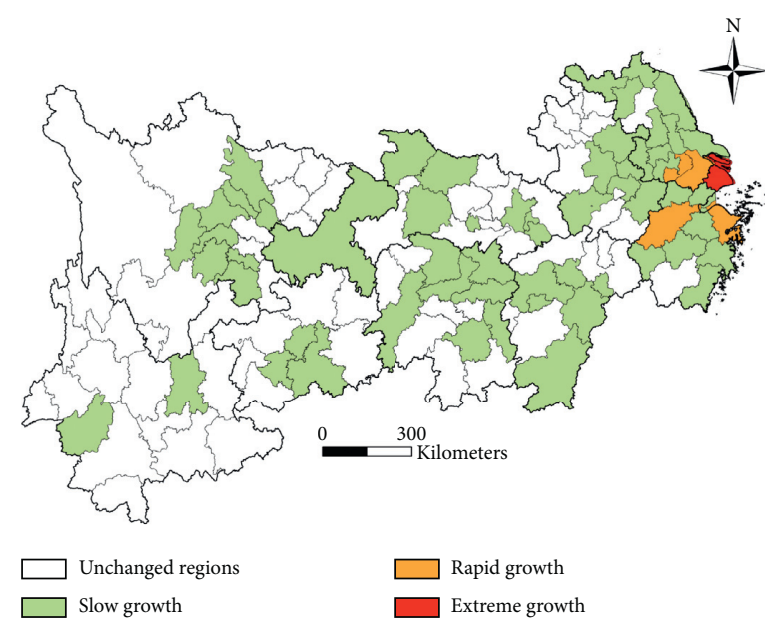

(a)

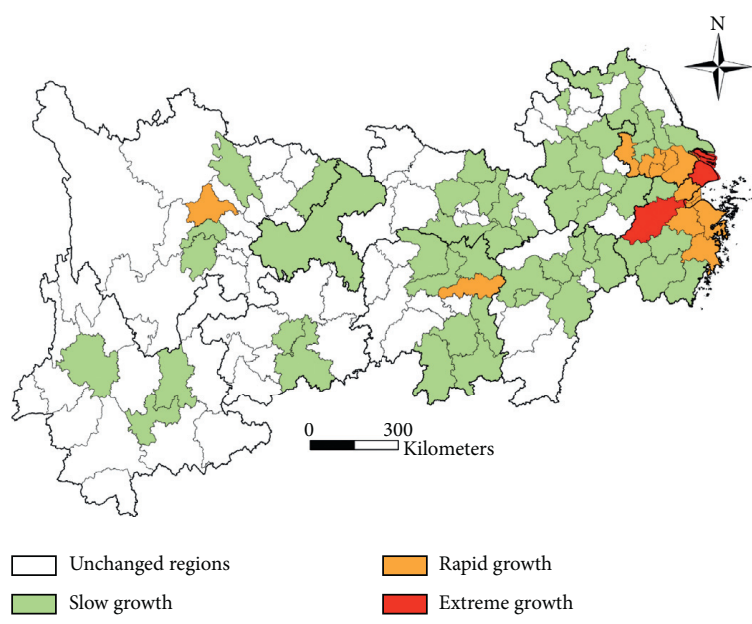

(b)

Figure 6: The classification of quantity growth trend of listed companies in the YEB region for (a) 2008 and (b) 2017.

TABLE 1: Global Moran's I index of spatial agglomeration of listed companies in the YEB region.

\begin{tabular}{lccc}
\hline & 2008 & 2013 & 2017 \\
\hline Moran's I & 0.129 & 0.228 & 0.283 \\
$\sum(I)$ & 0.00059 & 0.00073 & 0.0008 \\
$Z(I)$ & 5.616 & 8.699 & 10.323 \\
\hline
\end{tabular}

Note. $\sigma(I)$ is variance.

the natural breakpoint method to group the cities into four types according to local Moran's I index: high-high $(\mathrm{HH})$ agglomeration, low-low (LL) agglomeration, high-low (HL) agglomeration, low-high (LH) agglomeration. HH and LL agglomerations are the dominant agglomeration types in the YEB region that are distributed in the east and west regions, respectively. Having vibrant education and financial, technological, and information sectors, the Yangtze River Delta region has strong geographical attractiveness, forming $\mathrm{HH}$ agglomeration zones in Shanghai, Hangzhou, and Nanjing that are gradually spreading to the south. Due to the weak location conditions of the economic base and industrial business environment in western Yunnan and southern Sichuan, the overall development of the headquarters economy in the region has been restricted, and relatively stable LL agglomeration groups have been formed. In addition, Zhenjiang, Taizhou, Yangzhou, Ma'anshan, Xuancheng, and other cities have formed an LH cluster because of the relative disparity in business and financial environments with high-value areas. Affected by possible factors such as administrative division, topographic isolation, and weak industrial cooperation in the central and western regions, Wuhan, Changsha, Chengdu, Guiyang, Kunming, and other provincial capitals have insufficient linkages with other cities. The spatial diffusion effect of the headquarters economy remains weak and forms an HL agglomeration with fragmented distribution.

In terms of the evolution of the spatial center-of-gravity, the development center of listed companies shifted from the west towards the eastern coast, and the rate of migration slowed gradually. The spatial center-of-gravity changed between $30.46^{\circ}-30.52^{\circ} \mathrm{N}$ and $116.25^{\circ}-117.19^{\circ} \mathrm{E}$ and moved along the direction of "western-central-eastern" in Anqing city, Anhui. The migration speed of center-of-gravity decreased from $10.45 \mathrm{~km} / \mathrm{yr}(2008-2013)$ to $9.28 \mathrm{~km} / \mathrm{yr}$ (2013-2017). The standard deviation ellipse shifted 


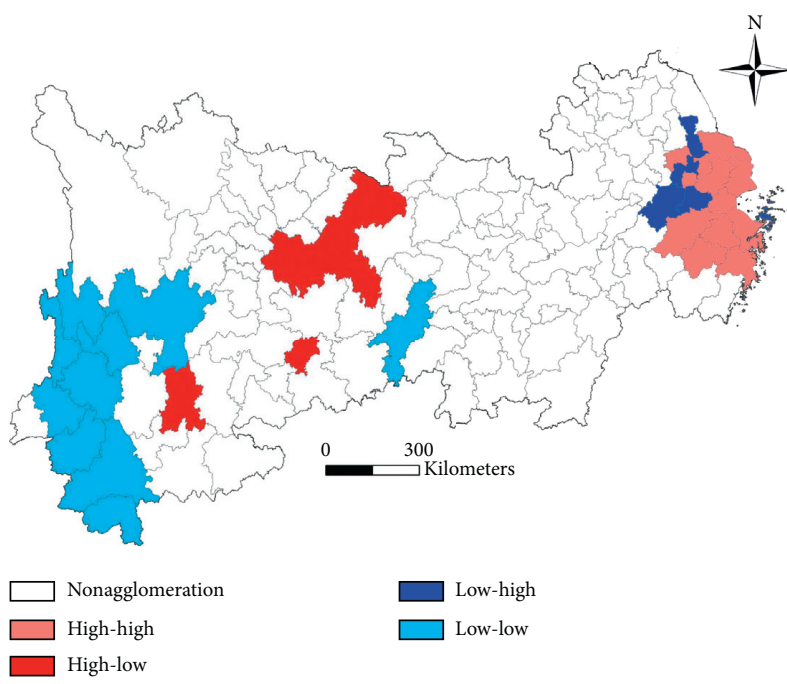

(a)

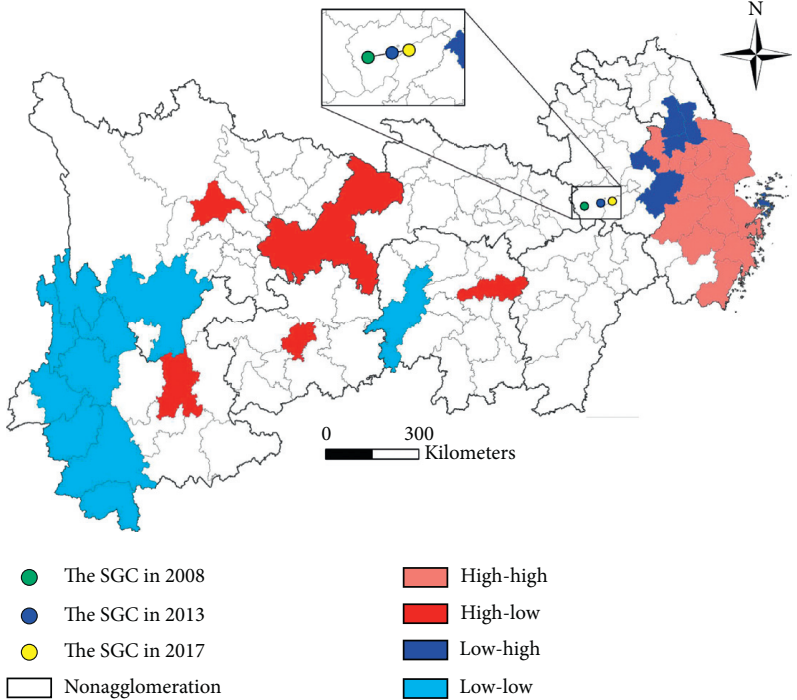

(b)

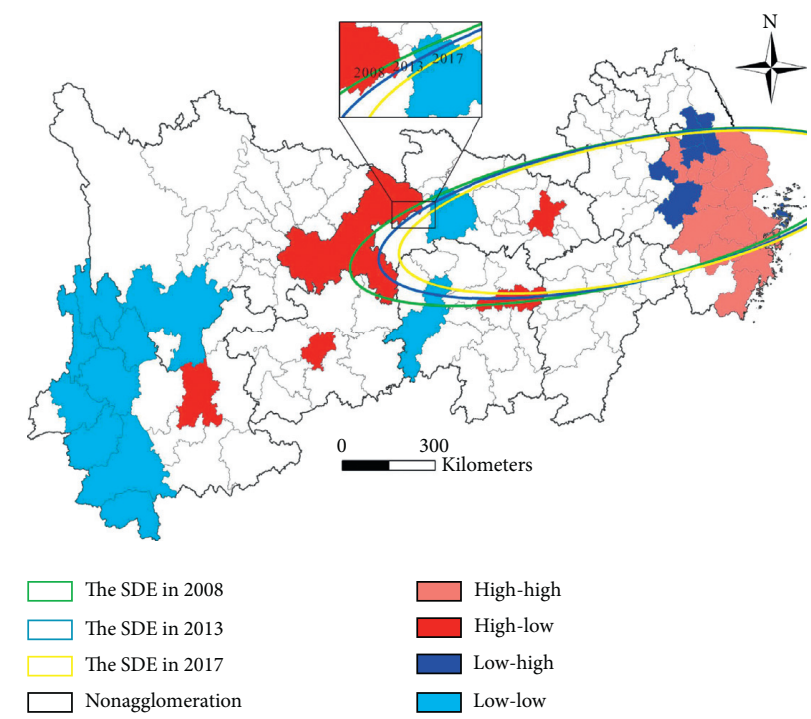

(c)

FIGURE 7: The spatial agglomeration classification, spatial gravity center (SGC), and standard deviation ellipse (SDE) of listed companies in the YEB region for (a) 2008, (b) 2013, and (c) 2017.

eastwards along with the migration of the spatial center-ofgravity, and the area was reduced from $606,750 \mathrm{~km}^{2}$ to $538,234 \mathrm{~km}^{2}$. The spatial center-of-gravity is the center of the ellipse formed by the high concentration of listed companies in the region, and its movement can reflect the extension direction of the high-value group with a large number of listed companies. The spatial center-of-gravity moves steadily eastward and the elliptical range continues to spread eastward, comprehensively showing that the attractive advantage created by the high economic strength, financial service level, and technological innovation environment in the eastern coastal area is still in the strengthening stage for listed companies. Meanwhile, the migration speed of the spatial center-of-gravity of listed companies to the east has slowed down, which is in line with the conclusion that the upward trend of the eastern region in the spatial distribution trend analysis has slowed down, indicating that, on the basis of the improvement of policy structure and regional development environment, the central and western regions will still have the opportunity to show a gradually optimized competitive advantage in the competition of spatial agglomeration of listed companies in the future.

\subsubsection{Spatial Evolution of the Industrialization Location} Layout of Listed Companies. Figure 8 reflects the spatial agglomeration characteristics among listed companies with different specialization levels from different industry types using the method of location quotient and Inverse Distance Weighted (IDW), and the index in the legend reflects the specialization levels of listed companies in each region. The results show that labor-intensive listed companies with high- 


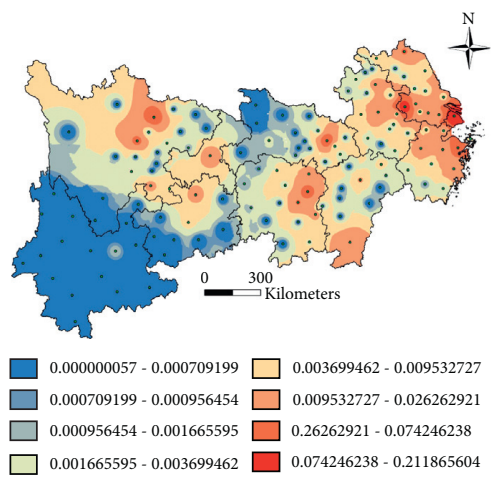

(a)

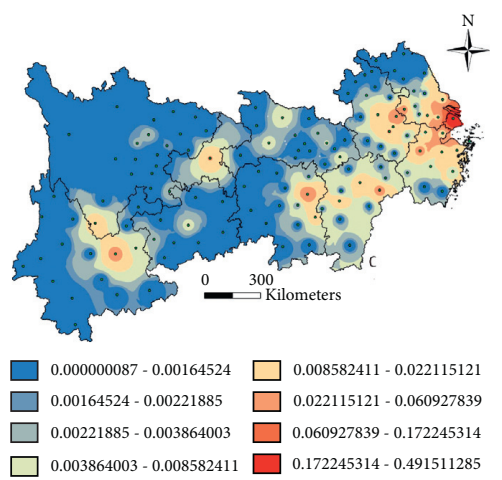

(d)

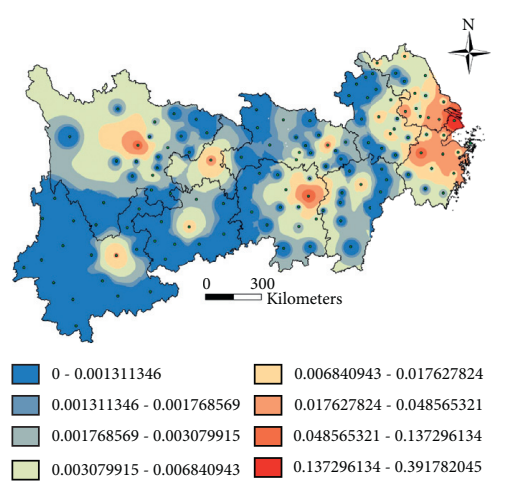

(g)

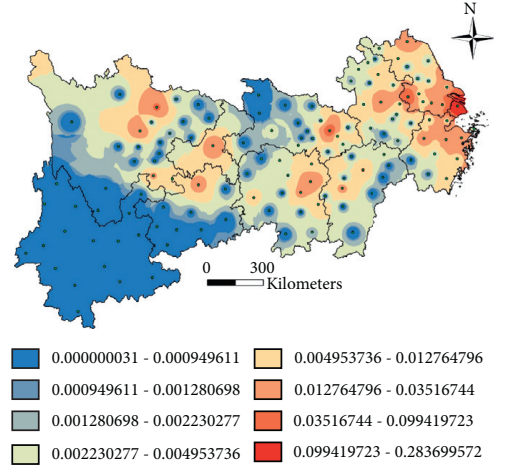

(b)

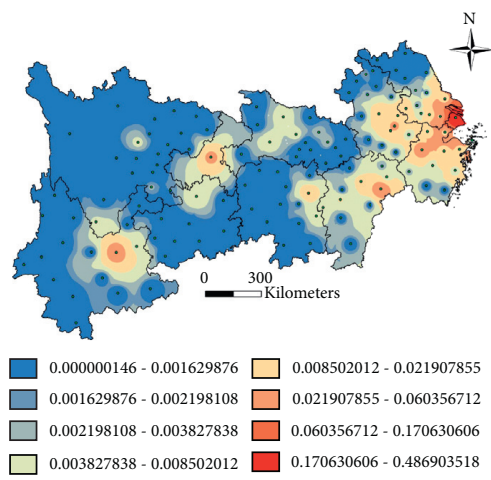

(e)

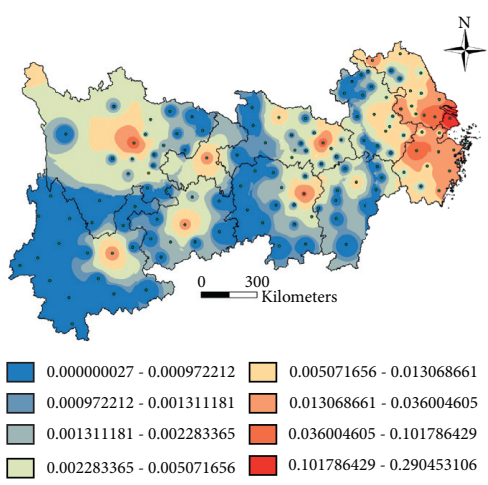

(h)

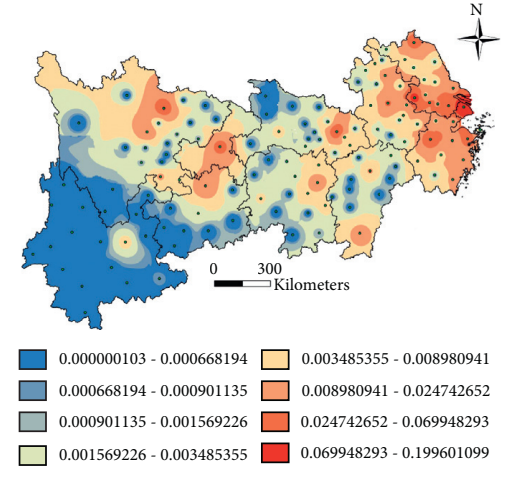

(c)

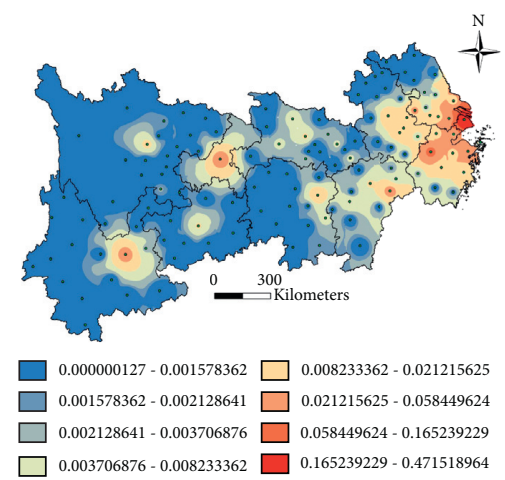

(f)

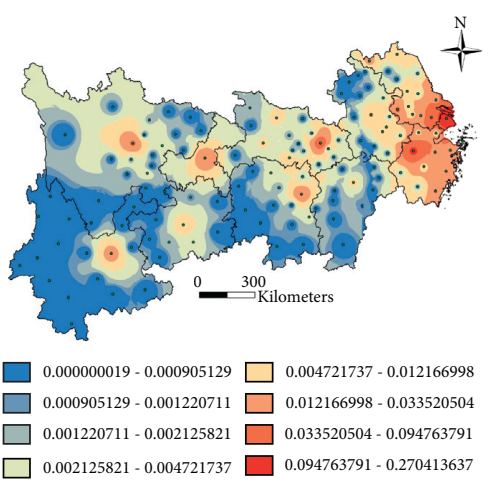

(i)

FIGURE 8: The spatial agglomeration of the specialization levels of listed companies in three major industrial types in (a, d, g) 2008; (b, e, h) 2013; and (c, f, i) 2017.

specialization levels gradually spread from a bead-chain distribution into flaky pattern distribution. In 2008, there were three major bead chains, namely, the Chengdu-Mianyang, Changsha-Zhuzhou-Xiangtan-Yueyang, and the Yangtze River Delta region with Nanjing, Shanghai, and Ningbo as centers. In 2017, the flaky high-value agglomeration area in the Yangtze River Delta was gradually formed, with Shanghai, Hangzhou, and Nanjing as core and Ningbo, Suzhou, and other places as the flanks. The trend of outward expansion and integration in the Chengdu-Mianyang and Chongqing-Guiyang chains continued increasing, in line with China's high-quality workforce migration trend (i.e., transfer to eastern coastal and provincial capitals) and the transition of labor-intensive enterprises towards high specialization in the Yangtze River Delta.

High capital-intensive listed companies with high-specialization levels tend to congregate in the Yangtze River Delta region, forming a layout structure more concentrated in the east than in the west. For 2008-2017, affected by the Yangtze River Delta integration strategy and regional capital factor allocation management experience, capital-intensive listed companies increasingly gathered in the Yangtze River Delta region and gradually formed a cluster distribution pattern with Shanghai as the core and Hangzhou, Ningbo, Jiaxing, and Suzhou as the series support. In the centralwestern regions, only Chengdu, Yingtan, Chongqing, 
Changsha, and other places have relatively high-levels of specialization, exhibiting pronounced polarized distribution characteristics.

Technology-intensive listed companies with high-specialization levels huddled in provincial capital cities and accelerated the diffusion around the urban agglomeration and metropolitan areas. In 2008, the high-specialization listed companies exhibited a fragmented pattern and were only located in central cities, such as Chengdu, Changsha, Hangzhou, Nanjing, and Shanghai. In 2013, a distribution area of high-specialization levels of technology-intensive listed companies was formed with Wuhan City Circle as the boundary in Hubei province. In 2017, the fragmented structure changed, and the high-value areas in the east region expanded southwards and westwards, covering much of the Yangtze River Delta's urban agglomeration. Due to transboundary cooperation among technology-intensive enterprises, a high-specialization cluster of technology-intensive listed companies was created in the Chengdu-Chongqing urban agglomeration. The urban agglomerations and metropolitan areas have become the first choice for technologyintensive listed companies with high-specialization levels.

3.2. Driving Mechanism Affecting Location Spatial Agglomeration of Listed Companies. The production and operation of listed companies require a large reserve of scientific and technological talents [18], the scale of urban industrial economy largely determines the degree of perfection of the regional industrial chain [19], and the degree of economic openness and geographic location affect the convenience for enterprises' foreign trade cooperation and transnational operations [7]. Besides, the strength of the local financial support and the policy environment determines the degree of infrastructure modernization and policy incentives, affecting the operating costs of listed companies [5]. Based on this, we select the factors that influence the location spatial agglomeration of listed companies, such as city scale, globalization level, technological input, knowledge spillover, and level of policy support. The following parameters were used: regional GDP, actual utilization of foreign capital, total expenditure on science and technology, number of institutions for higher learning, and total general government expenditure. The dummy variables, based on the urban administrative level (" 1 " for prefecture-level city, " 2 " for provincial capital city, and " 3 " for municipality directly under the central government), were used to reflect the geographic location parameter. The summary of indicator details is presented in Table 2. The data for these indicators were obtained mainly from the 2017 China Statistical Yearbook and the China City Statistical Yearbook, supplemented by provincial, city, and municipal statistical yearbooks. To analyze the driving mechanism by parts, we divided "typical regions" into low-level city network (0-20) and high-level city network (20-300) based on the number of city listed companies (see Figure 4). A comprehensive analysis of the driving factors of spatial agglomeration can then be implemented for the YEB region and "typical regions," in order to clarify the key elements of the city networks with different quantity of listed companies to achieve the headquarter economy development.

Table 3 summarizes the calculation results of SLM and SEM regression analysis. The OLS regression model has a poor fit ( $R$-squared is small; AIC and SC are both larger than SLM and SEM), primarily because it fails to consider the influence of the spatial dimensions of listed companies. The SLM and SEM incorporate lag and error terms into the framework that can explain the correlation between the spatial distribution of listed companies and the various driving factors. The results indicate that in both the overall region and the "typical regions", the SLM and SEM are both significant at the $0.1 \%$ level. The SEM has a larger loglikelihood value and smaller AIC and SC values than the SLM; the SEM's $R^{2}$ is also comparatively better. These findings suggest that the influence of uncertain factors on the spatial layout of listed companies cannot be ignored, and the SEM is more suitable in explaining the influencing factors for the spatial distribution of listed companies and is therefore used in the subsequent analyses.

In terms of the overall area, the top three factors are knowledge spillover level $(B=29.737)$, city scale $(B=20.756)$, and level of policy support $(B=17.225)$. This suggests that the intellectual resources of colleges and universities deliver highquality, innovative talents for enterprises, which are essential in the location selection of listed companies. The city scale positively affects regional economic strength, infrastructure construction level, consumer market capacity, and modern service level, which can ensure reliability in business operations. The high level of policy support can help in the effective implementation of government programs and market operations. It can also make contributions in terms of providing enterprises with financial support, promoting fair market competition, and encouraging transnational cooperation strategies. The results also show that the regression coefficients for technology development level and geographic locations are -20.327 and -17.931 , respectively. This suggests that while the technological input and the geographic location of Changsha, Wuhan, Chengdu, Ningbo, Suzhou, Taizhou, and other outside cities in the Yangtze River Delta have not been optimal, the enormous growth in the number of listed companies has weakened the overall influence of these two factors.

For low-level city network with few listed companies, the two main factors are city scale $(B=7.654)$ and knowledge spillover level $(B=5.055)$. This suggests a strong dependence of low-level city network on the scale of cities. Cities, particularly in the central and western regions, should prioritize in enhancing the capacity of industry support and economic development strength towards the development of headquarters economy. The impact of knowledge spillover is related to the demand for intellectual resources and skill competency in listed companies. In most cities in the central and western regions, limited resources in universities and the relative scarcity of high-quality talents can significantly inhibit the appeal of cities in attracting agglomeration of listed companies.

For high-level city network with a large number of listed companies, the top three determinants are knowledge spillover level $(B=37.815)$, policy support level $(B=15.471)$, 
TABLe 2: Details of the driving factors used in the model.

\begin{tabular}{|c|c|c|}
\hline $\begin{array}{l}\text { Driving } \\
\text { factors }\end{array}$ & Definition & Indicator \\
\hline City & $\begin{array}{l}\text { To some extent, affects the environment for the survival and development of listed } \\
\text { companies }\end{array}$ & GDP \\
\hline Globalization & $\begin{array}{l}\text { Affects the convenience of enterprises to carry out cross-border cooperation in } \\
\text { technology, capital, production, operation, and labor services }\end{array}$ & Actual utilization of foreign capital \\
\hline Technology & $\begin{array}{c}\text { To a certain extent, determines the ease of industrial transformation and product } \\
\text { power of listed companies }\end{array}$ & $\begin{array}{l}\text { Total expenditure on science and } \\
\text { technology }\end{array}$ \\
\hline Knowledge & $\begin{array}{c}\text { Affects the enterprise's production-university-research cooperation and } \\
\text { innovative atmosphere }\end{array}$ & $\begin{array}{l}\text { The number of ordinary institutions of } \\
\text { higher learning }\end{array}$ \\
\hline Policy & Affects the smooth implementation of the company's layout and business strategy & $\begin{array}{l}\text { The general public budget expenditure } \\
\text { of the government }\end{array}$ \\
\hline Location & $\begin{array}{l}\text { The administrative level of a city is directly related to the concentration of } \\
\text { resource elements and regional social and economic activities }\end{array}$ & Administrative level \\
\hline
\end{tabular}

Note. "City" is city scale; "globalization" is the globalization level; "technology" refers to the technological input; "knowledge" refers to the level of knowledge spillover; "policy" is the level of policy support; and "location" refers to the geographical location.

TABLE 3: Results of SLM and SEM regression analysis of each dimension.

\begin{tabular}{|c|c|c|c|c|c|c|}
\hline \multirow{2}{*}{ Level of quantity } & \multicolumn{3}{|c|}{ SLM } & \multicolumn{3}{|c|}{ SEM } \\
\hline & $\mathrm{a}$ & $\mathrm{b}$ & c & $\mathrm{a}$ & $\mathrm{b}$ & c \\
\hline City & $19.385^{* * *}$ & $7.334^{* * *}$ & $12.247^{* *}$ & $20.756^{* * *}$ & $7.654^{* * *}$ & $8.344^{*}$ \\
\hline Globalization & $1.862 *$ & $-0.982 *$ & $7.399^{*}$ & $2.527^{*}$ & $-0.966^{*}$ & $14.32^{* *}$ \\
\hline Technology & $-17.336^{* * *}$ & $-3.901 * *$ & $-24.783^{* * *}$ & $-20.327^{* * *}$ & $-3.66^{* *}$ & $-27.073^{* * *}$ \\
\hline Knowledge & $27.995^{* * *}$ & $5.541^{* * *}$ & $35.974^{* * *}$ & $29.737^{* * *}$ & $5.055^{* * *}$ & $37.815^{* * *}$ \\
\hline Policy & $15.732^{* * *}$ & $2.575^{* *}$ & $21.291^{* *}$ & $17.225^{* * *}$ & $2.999^{* *}$ & $15.471^{* *}$ \\
\hline Location & $-15.657^{* * *}$ & $2.332^{* *}$ & $-26.892^{* *}$ & $-17.931^{* * *}$ & $1.953^{* *}$ & $-21.025^{* *}$ \\
\hline R-squared & 0.928 & 0.732 & 0.951 & 0.935 & 0.735 & 0.956 \\
\hline Log-likelihood & -387.062 & -186.632 & -75.277 & -383.633 & -186.396 & -74.6621 \\
\hline AIC & 790.125 & 389.265 & 166.554 & 781.267 & 386.793 & 163.324 \\
\hline SC & 811.508 & 408.992 & 174.11 & 799.977 & 404.054 & 169.935 \\
\hline $\mathrm{N}$ & 107 & 88 & 19 & 107 & 88 & 19 \\
\hline
\end{tabular}

Note. $a$ indicates the YEB region; $b$ indicates low-level city network; $c$ indicates high-level city network. ${ }^{* * *} p<0.01 ;{ }^{* *} p<0.1 ;{ }^{*} p<0.05$. AIC means Akaike information criterion; SC is the Schwarz criterion.

and globalization level $(B=14.32)$. With the acceleration of industrial structure transformation and upgrading in the high-level city network, the demand for industry-universityresearch cooperation, technological innovation talents, and educational resources has increasingly become crucial in the modern high-end industrial system. Likewise, the strong influence of policy support suggests that policies relating to urban agglomeration planning and city construction have a considerable effect on shaping the location advantages in high-level city network. High-quality government service and work efficiency have provided significant contributions to the improvement of the business environment of listed companies. The impact of the level of globalization is prominent because high-level city network has a higher level of specialization, having stronger demands for international labor and transnational technology cooperation. The higher the level of globalization, the stronger the participation in the global industrial division of labor system, which may help companies to improve competitiveness in overseas markets and market visibility.

\section{Discussion}

4.1. Overall Distribution Structure Analysis. GIS spatial interpolation and TSA methods were employed to study the location selection characteristics of listed companies in the YEB region, showing the spatial distribution network of listed companies with the Yangtze River Delta region as the core and the following distribution trend: "the quantity of companies is high in the northeast and low in the southwest," similar to the findings of previous studies $[6,8,12]$. This verifies the disparity in headquarters economic development between the east and west regions of the YEB region and reaffirms the significant advantages of the Yangtze River Delta in attracting listed companies [20]. The scale of listed companies in the provincial capital cities of Chongqing, Chengdu, Changsha, Wuhan, Nanjing, and other cities increased rapidly at the end of the study period. This suggests that the regional development strategies and financial support policies, which are based on the provincial capital cities used as the core, have 
yielded significant results for enhancing the location attractiveness for listed companies. In order to boost the headquarters economy in the YEB region, the government has to recognize the spatial differences in the location selection process of listed companies and help improve the economic radiation capacity of the Yangtze River Delta region and provincial capital cities to the surrounding cities.

4.2. Spatial Agglomeration Evolution Analysis. The findings show that the listed companies in the YEB region have an apparent "Matthew effect." Listed companies had the Yangtze River Delta region as the first choice for their headquarter location, followed by provincial capitals. The location attraction of other cities in the central and western regions had been insufficient, leading to the formation of a strict urban hierarchy growth order [21]. The spatial autocorrelation analysis shows that the spatial agglomeration of listed companies in the YEB region has been increasing gradually, indicating that cities with high-scale listed companies have the ability to radiate economic activities and can form coordinated growth structures with surrounding cities. The spatial center-of-gravity shifted from the west to the east coast, but the rate of migration slowed. These findings highlight the strength of the eastern region in cultivating and attracting headquarters of listed companies. The results also suggest that the shifting government policies, construction strategies, and resource reallocation towards the central and western regions in recent years have enhanced competitiveness and attractiveness of these regions in the development of the headquarters economy. The distribution of industries by specialization levels shows that listed companies with high specialization tend to flock in eastern cities, provincial capitals, and urban agglomerations. Since modern urban systems are often better equipped to deal with interregional resource allocation and business interaction, they are more likely to strengthen the joint force of professional development.

4.3. Driving Factors Analysis. In comparison to the findings from previous studies that found regional economic scale as the principal determinant, our findings suggest that the level of knowledge spillover has become the primary factor affecting the location selection of listed companies in the YEB region [4]. This means that in the era of the knowledge economy, intellectual resources are becoming crucial elements for listed companies to create wealth and improve market competitiveness [22]. The important impact of city scale and knowledge spillover level for low-level city network indicates that strengthening their industrial construction capacity and investment in science and education resources is key to attracting the spatial agglomeration of listed companies. This supports China's current preferential policies towards the development of the central and western regions. Globalization was found to have a significant impact on high-level city network, which reflects a crucial requirement of listed companies in the east region for transnational operations and cooperation. In order to further develop the headquarters economy for this particular city type, vertical integration and extension of the industrial chain have to be strengthened, and transnational development strategies have to be implemented to improve the status of the international division of labor.

4.4. Policy Implications. In the postepidemic era, the global economic and financial landscape is facing in-depth adjustments; the listed companies in YEB region also have many problems, such as imbalanced spatial agglomeration layout and significant gap between east and west, which makes it urgent to rely on listed companies to accelerate resource integration and industrial innovation, and achieve the coordinated development of regional economy and industrial strength. (1) The knowledge spillover level, the city scale, and the level of policy support play important role for overall region. Cities in the YEB region should speed up the construction of school-enterprise alliances and the integration of production-education-research, strengthen financial investment in education, and cultivate corporate management talents and technological research teams. Meanwhile, the government should focus on the change of the global financial market and accelerate the reform and innovation of the domestic financial system, to provide a great policy environment for the development of listed companies. (2) The knowledge spillover level, policy support level, and globalization have made outstanding contributions to the layout of listed companies in high-level city network. The eastern cities, represented by Shanghai, Hangzhou, and Nanjing, should progress in cultivating high-end international talents, creating a highly conducive business environment, and pushing for industrial internationalization. At the same time, it is necessary to integrate into the construction of the national strategies, such as the Yangtze River Economic Belt and the Belt and Road Initiative, relying on the cross-regional alliance of industrial parks to strengthen the cooperation with cities in the central and western regions for enhancing the radiating and leading effect of the headquarters economy. Emerging cities in the central-western regions, represented by Chongqing, Wuhan, and Chengdu, should focus on the construction of more industrial parks and urban agglomerations and strengthen the cooperation in enterprise listing, cross-regional operation, and industrial chain construction with the marginal cities to consolidate their location attractiveness. (3) The city scale and knowledge spillover level are the most critical factors in cultivating and attracting the layout of listed companies in low-level city network represented by smalland medium-sized cities in the central and western regions. These cities should focus on improving their own industrial capacity, vigorously connect with the construction strategy of urban agglomeration and metropolitan area, transform industrial comparative advantages into city economic advantages, actively cultivate their talent teams, improve basic conditions for regional development, and attract the industrial transfer and spatial layout of listed companies. 


\section{Conclusion}

This study took all A-share listed companies in the YEB as the research object, established the framework "pattern evolution-typical alienation-driving mechanism," and explored the evolution of the spatial agglomeration and the driving mechanisms of listed companies from 2008 to 2017. An integrated method system was developed; it combines trend surface analysis, exploratory spatial data analysis, standard deviation ellipse, SEM regression, and SLM regression in the analysis. The main conclusions of the study are as follows.

The location selection of listed companies has gradually formed a spatial distribution network where the Yangtze River is the link, the provincial capital cities act as the fulcrum, and the Yangtze River Delta region serves as the agglomeration core. The spatial difference of the layout of listed companies persists, showing the following spatial distribution trend: "the quantity of companies is high in the northeast and low in the southwest."

The YEB region has formed a strict urban hierarchy growth order. The number of listed companies in most cities is unchanged or has slow growth. In the central and western regions, the pattern of scale transfer has gradually formed around the development of provincial capital cities. Spatial autocorrelation analysis shows that the spatial agglomeration of listed companies has become more pronounced. $\mathrm{HH}$ and LL agglomerations are the main agglomeration types and are found mainly in the east and west regions of the YEB region. The spatial center-of-gravity and the ellipse range have shifted from the west to the eastern coast, and the location selection of high-specialization levels of listed companies showed significant variations among the three major industry types (i.e., labor-intensive, capital-intensive, and technology-intensive).

Knowledge spillover level, city scale, and policy support level are the main driving factors for attracting listed companies in the YEB region. Low-level city network with few listed companies has heavy dependency on city scale and knowledge spillover levels. In high-level city network, aside from the level of knowledge spillovers and policy support, the level of globalization was found to be a crucial driving mechanism.

Based on the unbalanced tendency shown by the spatial agglomeration of listed companies in the YEB region and the dominant factors affecting the distribution of listed companies in different city networks, targeted development suggestions are put forward, such as accelerating the construction of school-enterprise alliances and the integration of production-education-research, relying on the construction of industrial parks and urban agglomerations, accelerating cross-regional collaboration, and improving industrial development capabilities.

This study still has several limitations, which can be improved in future studies. First, our analysis of the location spatial agglomeration characteristics of listed companies did not consider distribution elements, such as asset intelligence, profit levels, and debt structure. Second, due to difficulties in data acquisition, several driving factors were overlooked, such as geographical terrain, entrepreneur choice preference, and regional market conditions. Despite these research constraints, this study was able to establish the framework of "pattern evolution-typical alienation-driving mechanism" and explored the key factors for attracting listed companies in the YEB region at different levels. The results can provide a useful reference for local governments to optimize the conditions for attracting investment and urban infrastructure and promote the overall coordinated and sustainable development of the headquarters economy in the YEB region.

\section{Data Availability}

The research data used to support the findings of this study are available from the corresponding author upon request.

\section{Conflicts of Interest}

The authors declare that there are no conflicts of interest regarding the publication of this paper.

\section{Acknowledgments}

Special thanks are due to the professional language editing service from EditX. This research was funded by the Program of National Natural Science Foundation of China, under grant no. 41501173, and Talent Introduction Program Project of Southwest University, under grant no. SWU019020.

\section{References}

[1] D. Maditinos, Z. Sevic, and C. Tsairidis, "Intellectual capital and business performance: an empirical study for the Greek listed companies," European Research Studies Journal, vol. 3, pp. 145-168, 2017.

[2] M. D. Rice and D. I. Lyons, "Geographies of corporate decision-making and control: development, applications, and future directions in headquarters location research," Geography Compass, vol. 4, no. 4, pp. 320-334, 2010.

[3] J. Garcia-Algarra, G. G. Bengoechea, and M. L. MouronteLopez, "Reducing trade inequality: a network-based assessment," Complexity, vol. 2020, Article ID 1593215, 9 pages, 2020.

[4] L. Li, C. M. Li, Z. X. Dai et al., "Research on spatial-temporal change and mechanism of listed companies in China," Surveying and Mapping Science, vol. 44, pp. 324-329, 2019.

[5] J. P. Zhao and M. H. Lu, "Characteristics and influencing factors of spatial distribution of headquarters of listed firms in Beijing,” Economic Geography, vol. 40, pp. 12-20, 2020.

[6] L. Zhang, H. Zhang, and H. Yang, "Spatial distribution pattern of the headquarters of listed firms in China," Sustainability, vol. 10, no. 7, 2564 pages, 2018.

[7] H. F. Wang, X. Zhang, X. Xiong et al., "Spatial agglomeration and changing trend of China's bio-industry: based on empirical data analysis of listed companies," Economic Geography, vol. 38, pp. 101-107, 2018.

[8] Y. X. Zhong, Y. Fu, W. D. Guo et al., "Spatial pattern evolution and driving factors of China's listed companies," Scientia Geographica Sinica, vol. 38, pp. 485-494, 2018.

[9] S. Mariann, "Spatial distribution of the top 500 companies on regional and county levels in Hungary-a repeated analysis," Regional Statistics, vol. 7, pp. 148-170, 2017. 
[10] C. Gu, L. Hu, and I. G. Cook, "China's urbanization in 19492015: processes and driving forces," Chinese Geographical Science, vol. 27, no. 6, pp. 847-859, 2017.

[11] M. Manniste, A. Hazak, and E. Listra, "European listed companies' share price reactions to global credit crunch: typology of winners and losers," International Journal of Trade Economics and Finance, vol. 2, pp. 478-483, 2014.

[12] J. Y. Lin, "The study on the characteristics of regional distribution evolution and the path dependence of listed companies in China," Shanghai Economic Research, pp. 37-43, 2018.

[13] X. Xu, G. Yang, Y. Tan, J. Liu, and H. Hu, "Ecosystem services trade-offs and determinants in China's Yangtze River economic belt from 2000 to 2015," Science of The Total Environment, vol. 634, pp. 1601-1614, 2018.

[14] Y. Li, H. Shao, N. Jiang et al., "The evolution of the urban spatial pattern in the Yangtze River economic belt: based on multi-source remote sensing data," Sustainability, vol. 10, 2018.

[15] Y. Zhong, A. Lin, L. He, Z. Zhou, and M. Yuan, "Spatiotemporal dynamics and driving forces of urban land-use expansion: a case study of the Yangtze River economic belt, China," Remote Sensing, vol. 12, no. 2, p. 287, 2020.

[16] H. Wang and R. Zuo, "A comparative study of trend surface analysis and spectrum-area multifractal model to identify geochemical anomalies," Journal of Geochemical Exploration, vol. 155, pp. 84-90, 2015.

[17] F. Li, X. Wang, H. Liu et al., "Does economic development improve urban greening? Evidence from 289 cities in China using spatial regression models," Environmental Monitoring and Assessment, vol. 190, pp. 1-19, 2018.

[18] Z. Sun and L. P. Xiao, "Industrial Characteristics, Corporate governance and firm's R and D investment_- - evidence from A shares of listing corporation of strategic emerging industries in China," Journal of Economic Management, vol. 8, pp. 23-34, 2015.

[19] Y. M. Sun and X. W. Meng, "Research on macroeconomic environment, industry characteristics and zero debt behavior of listed companies," Macroeconomics, vol. 2, pp. 33-45, 2019.

[20] J. Li, X. Huang, M.-P. Kwan, H. Yang, and X. Chuai, "The effect of urbanization on carbon dioxide emissions efficiency in the Yangtze River Delta, China," Journal of Cleaner Production, vol. 188, pp. 38-48, 2018.

[21] E. Aksel, "Exploring economic development through headquarters: the spatial distribution of Turkey's large industrial enterprises and its implications for urban systems," Professional Geographer, vol. 68, pp. 138-148, 2015.

[22] G. Venanzoni, M. Carlucci, and L. Salvati, "Latent sprawl patterns and the spatial distribution of businesses in a southern European city," Cities, vol. 62, pp. 50-61, 2017. 